\title{
Clustering and Healthcare Costs With Multiple Chronic Conditions in a US Study
}

\author{
Cother Hajat $^{1 *}$, Yakir Siegal ${ }^{2}$ and Amalia Adler-Waxman ${ }^{3}$ \\ ${ }^{1}$ Public Health Institute, United Arab Emirates (UAE) University, Al Ain, United Arab Emirates, ${ }^{2}$ Deloitte Consulting LLP, New \\ York, NY, United States, ${ }^{3}$ Teva Pharmaceuticals Industries Ltd., Petah Tikva, Israel
}

Objective: To investigate healthcare costs and contributors to costs for multiple chronic conditions (MCCs), common clusters of conditions and their impact on cost and utilization.

Methods: This was a cross-sectional analysis of US financial claims data representative of the US population, including Medicare, Medicaid, and Commercial insurance claims in 2015. Outcome measures included healthcare costs and contributors; ranking of clusters of conditions according to frequency, strength of association and unsupervised (k-means) analysis; the impact of clustering on costs and contributors to costs.

\section{OPEN ACCESS}

Edited by:

Mihajlo Jakovljevic, Hosei University, Japan

Reviewed by:

Gregory Lubiani, Texas A\&M University Commerce,

United States

Simon Grima,

University of Malta, Malta

Márta Péntek,

Óbuda University, Hungary

${ }^{*}$ Correspondence:

Cother Hajat

Chajat@doctors.org.uk

Specialty section: This article was submitted to

Health Economics,

a section of the journal

Frontiers in Public Health

Received: 21 September 2020 Accepted: 02 December 2020

Published: 21 January 2021

Citation:

Hajat $C$, Siegal $Y$ and Adler-Waxman A (2021) Clustering and Healthcare Costs With Multiple Chronic Conditions in a US Study.

Front. Public Health 8:607528. doi: 10.3389/fpubh.2020.607528
Results: Of 1,878,951 patients, 931,045(49.6\%) had MCCs, 56.5\% weighted to the US population. Mean age was 53.0 years (SD16.7); 393,121(42.20\%) were male. Mean annual healthcare spending was $\$ 12,601$, ranging from $\$ 4,385$ (2 conditions) to $\$ 33,874$ (11 conditions), with spending increasing by 22 -fold for inpatient services, 6-fold for outpatient services, 4.5-fold for generic drugs, and 4.2-fold for branded drugs. Cluster ranking using the 3 methodologies yielded similar results: highest ranked clusters included metabolic syndrome (12.2\% of US insured patients), age related diseases $(7.7 \%)$, renal failure $(5.6 \%)$, respiratory disorders $(4.5 \%)$, cardiovascular disease(CVD) (4.3\%), cancers (4.1-4.3\%), mental health-related clusters (1.0-1.5\%), and HIV/AIDS (0.2\%). Highest spending was in HIV/AIDS clusters $(\$ 48,293)$, mental health-related clusters $(\$ 38,952-\$ 40,637)$, renal disease $(\$ 38,551)$, and CVD $(\$ 37,155)$; with $89.9 \%$ of spending on outpatient and inpatient care combined, and $10.1 \%$ on medication.

Conclusion and Relevance: Over $57 \%$ of insured patients in the US may have MCCs. MCC Clustering is frequent and is associated with healthcare utilization. The findings favor health system redesign toward a multiple condition approach for clusters of chronic conditions, alongside other cost-containment measures for MCCs.

Keywords: cardiovascular disease, chronic disease, multimorbidity, cancer, mental health, healthcare costs, disease clustering

\section{HIGHLIGHTS}

What is already known about the topic?

Despite one in three adults suffering from more than one chronic condition, little is known about the burden from MCCs. Some studies to date suggest markedly different disease, cost and societal burdens. Furthermore, certain conditions cluster together more frequently, however, no studies have reported on the impact that clusters have on the healthcare cost burden from MCCs in 
a comprehensive manner. Recent consensus statements have called for a specific focus on multiple chronic conditions.

\section{What does the paper add to existing knowledge?}

This study is one of the most comprehensive studies investigating contributors to costs in terms of number of patients included, representativeness of the US population and inclusion of the full range of chronic conditions.

What insights does the paper provide for informing healthcare-related decision making?

Of US insured patients, over 57\% may have multiple chronic conditions.

HIV/AIDS was the costliest cluster followed by clusters of mental and behavioral disorders, renal failure and CVD. Outpatient and inpatient services account for roughly $90 \%$ of health spending and medication for $10 \%$.

Health service utilization varies by number and clusters of conditions, with potential overutilization of specialist services and underutilization of primary care and psychiatric services.

\section{INTRODUCTION}

The increasing global burden of non-communicable diseases (NCDs), accounting for three in five of global deaths (1), has long been recognized as a global priority. Less attention has been given to the issue of multiple chronic conditions (MCCs), also termed multi-morbidity, despite one in three adults suffering from more than one chronic condition (2).

Evidence from a handful of studies reporting on the burden from MCCs to date suggest that this phenomenon results in markedly different disease, cost and personal burdens. Most studies have asserted a positive association between MCC and healthcare expenditures (3), some reporting a doubling in costs with each subsequent condition $(4,5)$. Studies suggest more complex inpatient and outpatient care utilization and use of more prescription medications (6-9).

Certain conditions cluster together more frequently such as stroke and Alzheimer's disease, and communicable conditions such as TB and HIV/AIDS with diabetes and CVD, respectively $(10,11)$. However, no studies have reported on the impact that clusters have on the healthcare cost burden from MCCs in a comprehensive manner.

Recent articles have called for a specific focus on multiple chronic conditions (10-12) and the Academy of Medical Sciences in the UK identified clustering of disease as a priority research area (13).

The objective of this article is to quantify healthcare spending in patients with MCCs using a comprehensive set of chronic conditions, identify the most important clusters and identify the key contributors to costs for MCC patients. The primary research questions were:

1. What are the healthcare costs and contributors to costs for patients with multiple chronic conditions?

2. What are the most important clusters of chronic conditions?

3. How does clustering of chronic conditions impact cost and contributors to costs?

\section{METHODS}

We used a random sample of IBM MarketScan ${ }^{\circledR}$ claims-based data (14) for US adults (age 18+ years) covered by insurance for the data year 2015, including the Commercial Claims and Encounters (CCAE) Database, the Medicare Supplemental Database, and the Multi-State Medicaid Database. The IBM MarketScan ${ }^{\circledR}$ claims databases contain de-identified, patientlevel health episode claims information for $>200$ million patients aggregated across multiple public and private health insurance providers. The claims data includes information on inpatient services, outpatient services and outpatient prescription drugs. The CCAE database covers patients with commercial insurance while the Medicare Supplemental Database and the Multi-State Medicaid Databases cover patients submitting claims through the public programmes of Medicare and Medicaid, respectively (15). The MarketScan ${ }^{\circledR}$ database utilizes standard international coding and the International Classification of Disease (16) was used to assign diagnoses. Random, representative samples of each of these three databases were sourced from IBM MarketScan ${ }^{\circledR}$ as a basis for this analysis.

Patients with two or more chronic conditions from the Agency for Healthcare Research and Quality (AHRQ) list of 69 chronic conditions which relies on ICD9 and ICD10 coding systems (17) were included. Patients with more than 11 conditions, equating to $59,432(6.4 \%)$ of MCC patients in the sample, were omitted due to inadequate sub-group numbers.

The main purpose of this study was to understand drivers of healthcare spend for patients with key clusters of multiple chronic conditions. In the absence of agreed upon criteria and methodologies for determining key clusters, we employed a twostep process to identify and select clusters for further analysis, utilizing three different methodologies to shed light on different aspects of key clusters.

Step 1 used three different methods for ranking and characterizing clusters: Method A: Identify and rank the top 25 co-morbid condition pairs based on prevalence-i.e., highest frequency of occurrence in the sample population.

Method B: Identify and rank the top 25 co-morbid conditions pairs based on strength of association-i.e., highest probability of condition 2 being present in a patient if condition 1 is present.

Method C: Conduct an unsupervised k-means clustering analysis to identify clustering without constraining to condition pairs. K-means is an unsupervised learning method without reliance on a "dependent" variable (18). K-means clustering optimizes the within group sum of squares i.e., it assigns observations to a cluster based on how close (Euclidean distance) it is to the cluster centroid. Each patient was assigned to a disease cluster based on Euclidean distance of their disease vectors to the cluster centroids (18). The clusters are reported in the results tables characterized by the base conditions which strongly associate with the cluster (i.e., are present in $>95 \%$ of patients in that cluster), as well as other conditions more moderately associated with the cluster (present in $20-95 \%$ of patients in that cluster). Step 2 was to select 10 clusters to investigate further with respect to cost driver analysis from the "top" clusters from Step 1 based on frequency, strength of association and k-means 
TABLE 1 | Characteristics of patients included.

\begin{tabular}{|c|c|}
\hline \multicolumn{2}{|l|}{ Characteristic } \\
\hline Number with multiple chronic conditions & $931,045(49.6 \%)$ \\
\hline Age years: mean (SD) & $53.04(16.66)$ \\
\hline Male $n(\%)$ & $393,121(42.20 \%)$ \\
\hline \multicolumn{2}{|l|}{ Health Coverage: $n(\%)$} \\
\hline Commercial (CCAE) & $476,879(51.23 \%)$ \\
\hline Medicaid & $270,092(29.00 \%)$ \\
\hline Medicare & $184,074(19.77 \%)$ \\
\hline \multicolumn{2}{|l|}{ Number of chronic conditions: } \\
\hline $2 n(\%)$ & 201,255 (21.60\%) \\
\hline $3 n(\%)$ & $167,651(18.00 \%)$ \\
\hline $4 n(\%)$ & $134,020(14.40 \%)$ \\
\hline $5 n(\%)$ & $103,575(11.10 \%)$ \\
\hline $6 n(\%)$ & $78,844(8.47 \%)$ \\
\hline $7 n(\%)$ & $60,056(6.45 \%)$ \\
\hline $8 n(\%)$ & $45,449(4.88 \%)$ \\
\hline $9 n(\%)$ & $34,649(3.72 \%)$ \\
\hline $10 n(\%)$ & $26,078(2.80 \%)$ \\
\hline $11 n(\%)$ & $20,036(2.15 \%)$ \\
\hline \multicolumn{2}{|l|}{ Annual Healthcare spending US\$: mean(SD) } \\
\hline Overall & $12,601(36,329)$ \\
\hline \multicolumn{2}{|l|}{ By type of coverage: } \\
\hline Commercial (CCAE) & $10,571(28,352)$ \\
\hline Medicaid & $11,729(38,518)$ \\
\hline Medicare & $19,139(48,596)$ \\
\hline
\end{tabular}

clustering. The process involved selecting 10 anchor conditions or condition clusters of interest based primarily on their rank in the three analyses in Step 1, and characterizing the co-morbid prevalence of other conditions in the populations defined by the anchor conditions or condition clusters. Whilst primarily relying on rank from Step, clustering around HIV/AIDS was included for further analyses as a globally-relevant cluster of a chronic communicable condition of relevance to global populations.

Contributors to costs that were investigated included: age, sex, number of conditions, clustering of conditions, site of care settings (inpatient, outpatient), branded and generic medications, and of type of medical services provided: specialty procedures and diagnostics, primary care, emergency visits and psychiatric services. Definitions of healthcare spending are detailed in the technical supplement.

To make the results representative of the US insured population distribution, scaling factors were used to weight samples from each coverage type to the corresponding US adult (18+) insured population from year 2015 (including 134.1 million CCAE, 43.3 million Medicare, and 29.6 million Medicaid insured population) (19).

\section{Statistical Analysis}

Analyses were conducted using the software package $\mathrm{R}$, version 3.4.0 (2017-04-21). Anova testing was used to determine the statistical significance of differences in costs (for each subcategory e.g., outpatient costs, inpatient costs, medication costs) between clusters (at the 95\% significance level) adjusted for age and sex. Cancers were stratified by male and female demographics of the sample and reported as male and female types, adjusted for age only. All results were reported after weighting to the US population other than the crude figures used for reporting the study sample patient characteristics (Table 1).

As coverage type criteria include age, comparisons between coverage types were not adjusted by demographic factors. Other patient factors such as socio-economic status and ethnicity were not available.

\section{Patient and Public Involvement}

This work forms part of a broader study in which focus group work was conducted on patients with MCCs to elicit their main struggles and concerns and the terminology used in discussing their conditions. These qualitative insights were published in a white paper (11) and the current study aims to answer the quantitative research questions.

\section{RESULTS}

Table 1 reports characteristics of the study sample. The data comprised $51.2 \%$ of CCAE, $29.0 \%$ Medicaid, and 19.8\% Medicare patients. Of an initial sample of $1,878,951$ subjects, at-least 2 chronic conditions were found in 931,045 (49.6\%); when scaled to the US population, this would equate to $56.5 \%$. Mean age was 53.0 years (SD16.7); 393,121 (42.20\%) were male and 871,613 with between 2 and 11 conditions were further analyzed. Mean annual healthcare spending was $\$ 12,601$, varying between the types of insurance at $\$ 10,571$ for Medicaid, $\$ 11,730$ for Medicare, and $\$ 19,139$ for CCAE $(p<0.001)$.

Figure 1 shows mean healthcare spending per patient and contributors to costs, according to the number of chronic conditions. Average healthcare spending per annum for those with two conditions was $\$ 4,385$, increasing 8 -fold to $\$ 33,874$ for those with 11 or more conditions. Whilst the absolute values increased, the percentage change was non-linear, showing a consistently gradual decrement from $33 \%$ (shift from two to three conditions) to $18 \%$ (shift from 10 to 11 conditions). Inpatient costs accounted for the greatest shift in both absolute and relative amounts. The relative increase in healthcare spending between patients with 2 and 11 conditions was 22 -fold for inpatient costs, 6-fold for outpatient costs, 4.5 -fold for generic drugs, and 4.2-fold for branded drugs.

Further analysis of the purely medical contributors to costs for MCC patients showed that between having 2 and 11 conditions, healthcare spending increased by 24 -fold for inpatient services, 8 -fold for speciality procedure and diagnostics, 6-fold for emergency visits, and 4-fold for both primary care services and psychiatric services.

Table 1 and Supplementary Table 1 show that average spending per annum was highest for Medicare at $\$ 19,129$ and considerably lower for both Medicaid at $\$ 11,783$ and CCAE at $\$ 10,572(p<0.001)$. Younger patients on Medicaid had higher spending on male cancers, renal failure, and HIV/AIDS whilst 


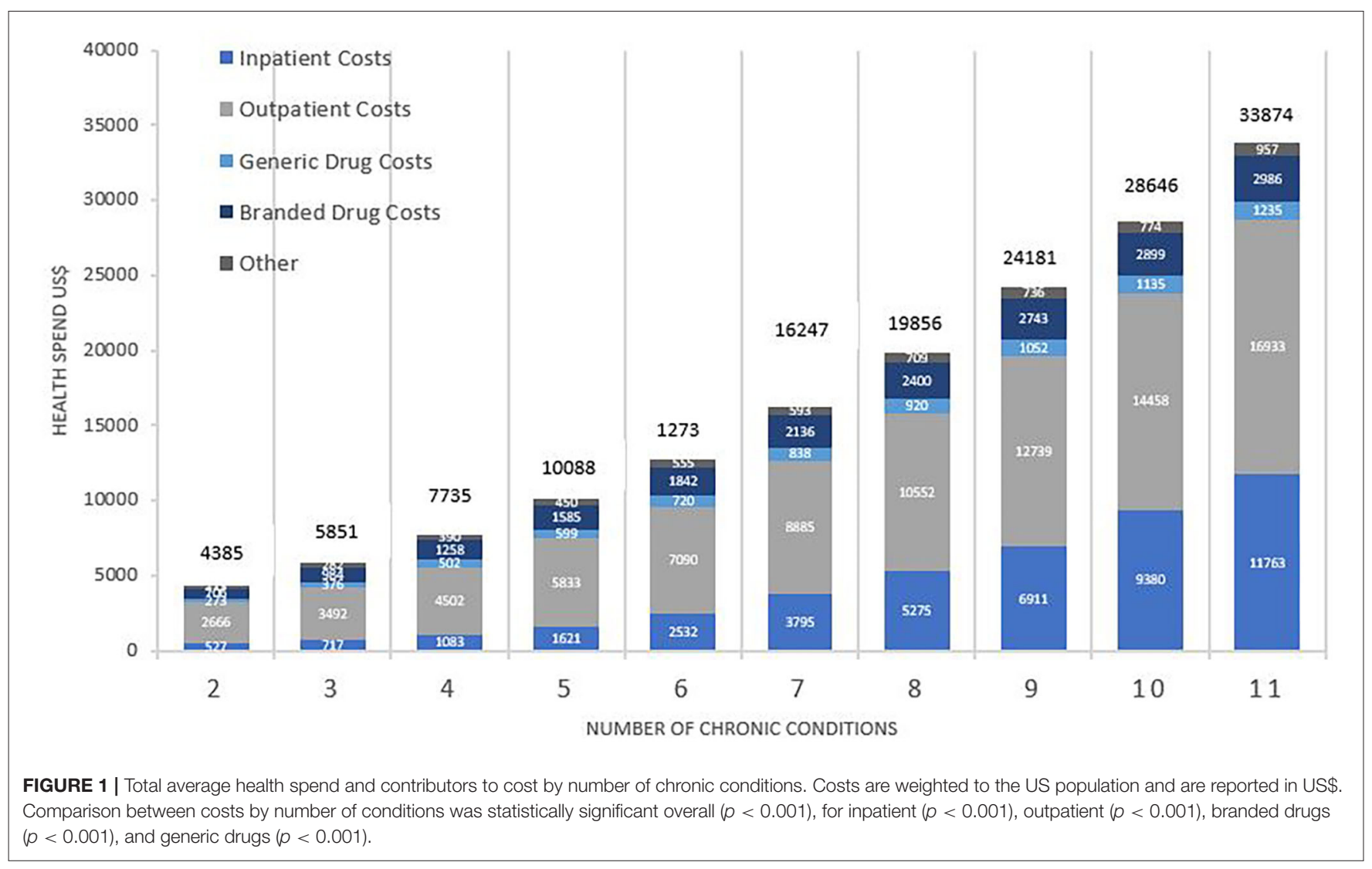

older patients on Medicare had higher spending for clusters associated with mental health problems, age-related disease and respiratory problems. Table 1 shows that the overall average spending is higher in Medicare than in CCAE, however the Supplementary Table 1 shows that when number of conditions is held fixed, Medicare spending is lower than CCAE due to typically lower reimbursement in Medicare compared with CCAE for any given condition.

Table 2 shows the 10 clusters included in further analyses; Supplementary Tables 2-4 show the list of top 25 clusters ranked by frequency, strength of association, and unstructured $\mathrm{k}$-means clustering from which the 10 clusters were selected. Among these were metabolic syndrome, present in $12.2 \%$ of the insured population and predominantly including hypertension, high cholesterol and diabetes mellitus. Renal failure (present in 5.6\%) and cancers (present in 4.1-4.3\%) clustered with hypertension, high cholesterol, diabetes, and other neurological disorders, amongst other conditions. Clusters of age-related diseases (present in 7.7\%) included osteoarthritis, hypertension and high cholesterol, and cardiovascular disease (CVD), present in $4.3 \%$, included hypertension, coronary artery disease (CAD), high cholesterol and cardiomyopathy. Respiratory disorders (present in 4.5\%) including chronic obstructive pulmonary disease (COPD) and allergy, clustered with hypertension, high cholesterol, peptic ulcer disease (excluding bleed), depression and other neurological disorders. Mental health disorder clusters, including depression and anxiety, were present in $1.0-1.5 \%$ and clustered with chronic pain, hypertension, high cholesterol, diabetes, other neurological disorders, and alcohol abuse. The HIV/AIDS cluster was present in $0.2 \%$ of the insured population and occurred with hypertension, high cholesterol, alcohol abuse, depression, and weight loss.

Outputs from the three different methods of ranking clusters (Step 1 in the Methods section), are reported in Supplementary Tables 2-4. The three methods yielded the same conditions for the majority of the top 25 clusters with clustering of high cholesterol with hypertension, diabetes with hypertension, high cholesterol with other endocrine disorders and osteoarthritis with hypertension ranking highly. Of the top 25 condition pairs by strength of association, only three individual conditions did not also appear in the top 25 by frequency, namely coagulopathy, blood loss anemia, and cystic fibrosis.

Figure 2 shows the average annual healthcare spending and contributors to costs by clusters. The highest spending was for patients with the HIV/AIDS cluster at $\$ 48,293$ per patient per annum, predominantly driven by the cost of branded drugs costing on average $\$ 21866$ (45.3\%) of their total spending. Subsequent ranks by spending included the clusters of mental/physical debilitation at $\$ 40,637$, mental health disorders at $\$ 38,952$, renal disease at $\$ 38,551$ and $C V D$ at $\$ 37,155$, with $45-50 \%$ of the healthcare spending on outpatient care, 
TABLE 2 | Key Clusters of chronic conditions.

\begin{tabular}{|c|c|c|c|c|}
\hline Cluster name & $\begin{array}{l}\text { Conditions with strong } \\
\text { associations* (>95\%) }\end{array}$ & Conditions with moderate associations* (20-95\%) & $\begin{array}{l}\text { Sample } \\
\text { frequency } n(\%)\end{array}$ & $\begin{array}{l}\text { US insured } \\
\text { population } \\
\text { frequency } n(\%)^{* \star}\end{array}$ \\
\hline $\begin{array}{l}\text { Metabolic } \\
\text { syndrome }\end{array}$ & $\begin{array}{l}\text { Hypertension } \\
\text { High Cholesterol } \\
\text { Diabetes }\end{array}$ & $\begin{array}{l}\text { Eye problems; other neurological disorder; other endocrine } \\
\text { disorder; coronary artery disease; osteoarthritis; weight-loss; } \\
\text { obesity; chronic obstructive pulmonary disease (COPD) }\end{array}$ & $\begin{array}{l}110,946 \\
(11.9 \%)\end{array}$ & $\begin{array}{l}14,257,585 \\
(12.2 \%)\end{array}$ \\
\hline $\begin{array}{l}\text { Age-related } \\
\text { disease }\end{array}$ & $\begin{array}{l}\text { Osteoarthritis } \\
\text { Hypertension } \\
\text { High Cholesterol }\end{array}$ & $\begin{array}{l}\text { Diabetes; other neurological disorder; eye problems; other } \\
\text { endocrine disorder; peptic ulcer disease exclude bleed; coronary } \\
\text { artery disease }\end{array}$ & $65,356(7.0 \%)$ & $\begin{array}{l}8,990,408 \\
(7.7 \%)\end{array}$ \\
\hline Renal failure & Renal Failure & $\begin{array}{l}\text { Hypertension; high cholesterol; eye problems; diabetes; other } \\
\text { neurological disorders; weight loss; cardiac arrhythmias; coronary } \\
\text { artery disease }\end{array}$ & $50,373(5.4 \%)$ & $\begin{array}{l}6,602,939 \\
(5.6 \%)\end{array}$ \\
\hline Respiratory & $\begin{array}{l}\text { Allergy } \\
\text { COPD }\end{array}$ & $\begin{array}{l}\text { Hypertension; high cholesterol; peptic ulcer disease exclude } \\
\text { bleed; depression; other neurological disorders }\end{array}$ & $44,486(4.8 \%)$ & $\begin{array}{c}5,234,597 \\
(4.5 \%)\end{array}$ \\
\hline $\begin{array}{l}\text { Cardiovascular } \\
\text { disease }\end{array}$ & $\begin{array}{l}\text { Hypertension } \\
\text { CAD Cardiomyopathy } \\
\text { High Cholesterol }\end{array}$ & $\begin{array}{l}\text { Diabetes; cardiac arrhythmias; eye problems; COPD; other } \\
\text { neurological disorders; congestive heart failure; osteoarthritis }\end{array}$ & $34,807(3.7 \%)$ & $\begin{array}{c}4,982,731 \\
(4.3 \%)\end{array}$ \\
\hline Cancer female & $\begin{array}{l}\text { Malignant Neoplasm } \\
\text { (females) }\end{array}$ & $\begin{array}{l}\text { Hypertension; high cholesterol; other endocrine disorder; eye } \\
\text { problems }\end{array}$ & $37,062(4.0 \%)$ & $\begin{array}{c}4,992,607 \\
(4.3 \%)\end{array}$ \\
\hline Cancer male & $\begin{array}{l}\text { Malignant Neoplasm } \\
\text { (males) }\end{array}$ & Hypertension; high cholesterol; eye problems; diabetes & $32,291(3.5 \%)$ & $\begin{array}{c}4,788,380 \\
(4.1 \%)\end{array}$ \\
\hline $\begin{array}{l}\text { Physical/mental } \\
\text { debilitation }\end{array}$ & $\begin{array}{l}\text { Depression } \\
\text { Chronic Pain }\end{array}$ & $\begin{array}{l}\text { Hypertension; alcohol abuse; other neurological disorder; anxiety; } \\
\text { peptic ulcer disease exclude bleed; COPD; diabetes; high } \\
\text { cholesterol; weight loss; liver disease; enterocolitis }\end{array}$ & $23,897(2.6 \%)$ & $\begin{array}{l}1,802,778 \\
(1.5 \%)\end{array}$ \\
\hline $\begin{array}{l}\text { Mental health } \\
\text { disorders }\end{array}$ & $\begin{array}{l}\text { Depression } \\
\text { Anxiety Hypertension }\end{array}$ & $\begin{array}{l}\text { High cholesterol; other neurological disorder; alcohol abuse; } \\
\text { peptic ulcer disease exclude bleed; COPD; diabetes; osteoarthritis }\end{array}$ & $12,652(1.4 \%)$ & $\begin{array}{l}1,147,493 \\
(1.0 \%)\end{array}$ \\
\hline HIV/AIDS & HIV/AIDS & $\begin{array}{l}\text { Hypertension; high cholesterol; alcohol abuse; depression; weight } \\
\text { loss }\end{array}$ & $2,890(0.31 \%)$ & $\begin{array}{c}252,688 \\
(0.2 \%)\end{array}$ \\
\hline
\end{tabular}

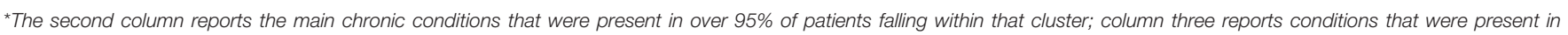
$20-95 \%$ of patients within that cluster. ${ }^{* *}$ Weighted and extrapolated to the US insured population.

$40-45 \%$ on inpatient care and $10 \%$ on medication costs. In addition to these clusters, others that were associated with "other neurological disorders" accounted for higher healthcare spending in general.

Health Service Utilization was dependent on both the number and cluster of conditions. The proportion of total health spending on inpatient costs increased with each additional condition from $\$ 515(20.7 \%)$ for 2 conditions to $\$ 12,292$ (47.8\%) with 11 conditions. The proportion of total health spending on primary care services decreased with each additional condition from $\$ 362$ (14.6\%) for 2 conditions to 1,490 (5.8\%) for 11 conditions. Figure 3 shows the pattern of utilization of health services by cluster. Inpatient services accounted for over half of medical health spending for many of the clusters, followed closely by spending on specialty procedures and diagnostics. Spending on psychiatric services was low for all clusters, ranging from $\$ 58$ $(0.2 \%)$ in metabolic syndrome to $\$ 210$ (1.4\%) in the HIV/AIDS cluster and $\$ 418(1.5 \%)$ in the mental health disorder cluster.

Healthcare spending by clusters stratified by age group followed predicted patterns of higher spending for older age groups in the clusters of metabolic syndrome, mental health disorders, physical and mental debilitation, HIV/AIDS, respiratory and age-related conditions. However other clusters such as CVD, female cancers and renal failure varied less between age groups. Mean healthcare spending for CVD was $\$ 34,485$ for
18-44 year olds and $\$ 38,175$ for those aged 85 and over, with similar outpatient, inpatient and generic drug costs. Spending on branded drugs accounted for a large proportion of the variance $(\$ 3,121$ and $\$ 2,703$ in ages $45-64 \& 65-84$, respectively compared with $\$ 1932$ and $\$ 1,545$ in ages $18-44$ and $>85$, respectively; $p<$ $0.001)$. Male cancers are costlier in younger age groups $(\$ 42,118$ for ages $18-44$ compared with $\$ 33,206$ for age $85 ; p<0.001$ ) due to the specific types of cancer seen in younger men.

\section{DISCUSSION}

This study represents one of the most comprehensive studies to date to investigate contributors to costs in terms of number of patients included, representativeness of the US population and because it investigates the full range of, rather than selected, chronic conditions.

Key findings include:

1. In this large US insured patient sample, 50\% had multiple chronic conditions.

2. Costs of healthcare spending increase non-linearly with each subsequent condition. Our study shows a relatively smaller increment in healthcare spending compared with previous smaller published studies (10), and that the relative increase tapers off with each subsequent chronic condition. 


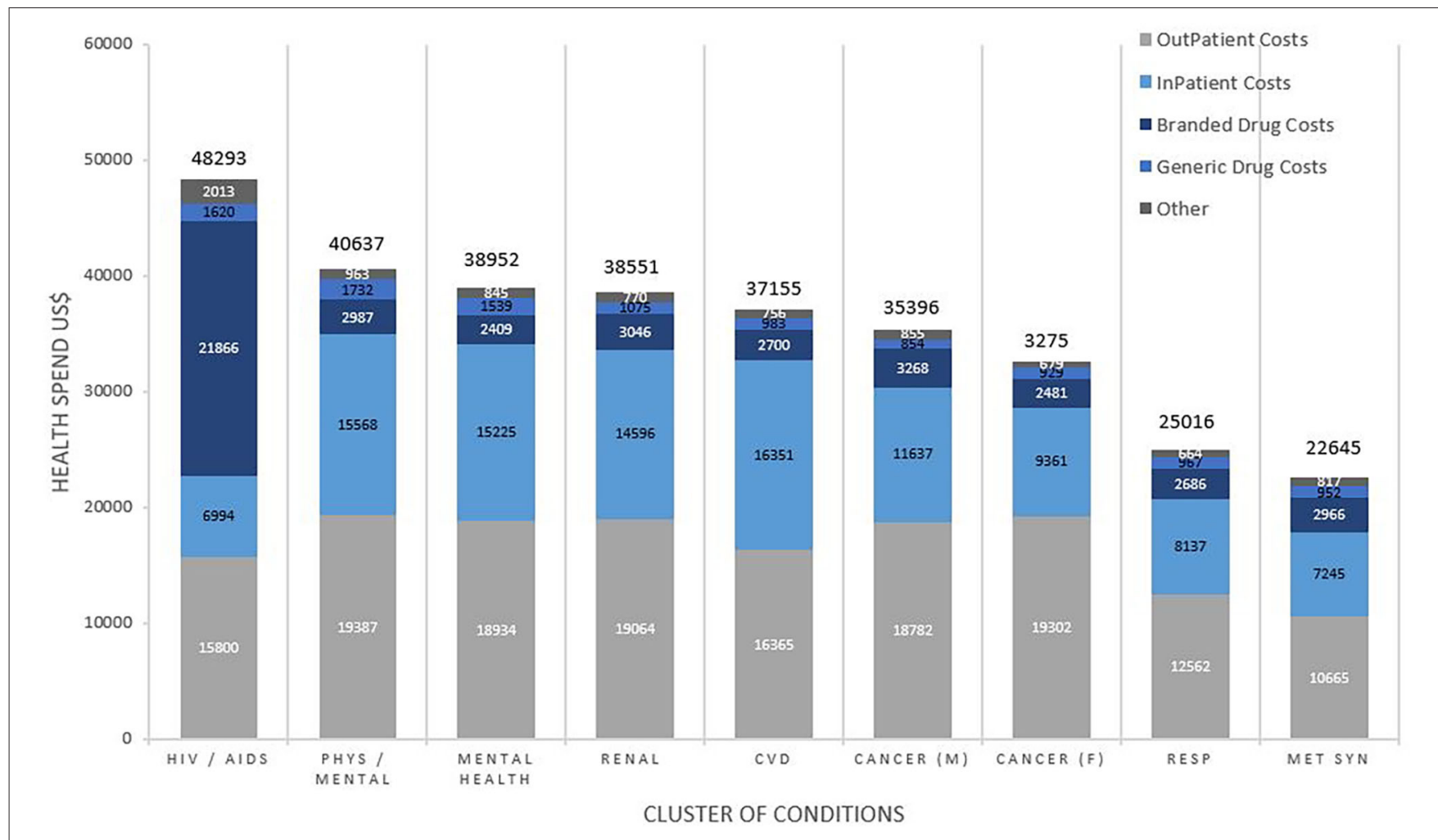

FIGURE 2 | Total average health spend and contributors to cost by cluster of conditions. Costs are weighted to the US population and reported in US\$. Comparisons for cost between clusters of conditions were statistically significant overall $(p<0.001)$, for inpatient $(p<0.001)$, outpatient $(p<0.001)$, branded drugs $(p<0.001)$, and generic drugs $(p<0.001)$.

3. Overall, inpatient costs accounted for the highest increase with each subsequent condition, with a 24 -fold increase between patients with 2 and 11 conditions, with considerable variation according to the "cluster" of conditions.

4. The 10 key clusters selected for more in-depth analysis included metabolic syndrome (present in 12\%), chronic renal failure $(8 \%)$, age related diseases $(7 \%)$, respiratory disorders (4.5\%), CVD (4\%), cancers (4\%), and mental and behavioral disorders (1-1.5\%). In addition, the HIV/AIDS cluster, of particular interest to LMIC settings, was present in $0.2 \%$.

5. Conditions occurring in over $95 \%$ of patients with these clusters included hypertension, high cholesterol, diabetes, CVD, depression, anxiety, chronic pain, osteoarthritis, allergy, COPD, male and female cancers, chronic renal failure, and HIV/AIDS.

6. HIV/AIDS was the costliest cluster due to $45 \%$ of total spending on branded drugs. This was followed by clusters of mental and behavioral disorders which were second and third most costly and, renal failure and CVD at fourth and fifth most costly, with outpatient and inpatient services accounting for roughly $90 \%$ of health spending.

7. Health service utilization varied by number of condition and clusters, with possible overutilization of specialist services and underutilization of primary care and psychiatric services in those with additional chronic conditions and certain clusters.

\section{Frequency Rates}

Our sample of 1 year of hospital episode data showed that exactly a half (56.5\% scaled to the US population) of patients had atleast 2 chronic conditions. However, as this is a patient sample it does not seek to represent the US population prevalence rate which would be expected to be lower due to the presence of nonhealthcare seeking adults. Nonetheless, the rates are within range of previously reported rates.

Prevalence estimates for MCC are highly heterogeneous with methodological differences such as age, the number of chronic conditions included and whether the outcomes are self-reported or verified leading to estimates that may vary up to 3-fold. Prevalence estimates for MCC range from 25.5\% in the US (for 10 chronic conditions), increasing in the US to $50 \%$ for ages 45 to 65 and $81 \%$ for ages over 65 years (20), 16\% in the UK (for 17 chronic conditions) to $58 \%$ (for 114 chronic conditions) (21), $45 \%$ in China to $71 \%$ in Russia in those aged over 50 (22) and just $9.4 \%$ in India $(23)$.

\section{Costs in Previous Literature}

There is considerable variation in the magnitude of resource utilization reported between studies, health systems and data sources. Our findings align with existing evidence that MCC patients experience more complex inpatient and outpatient care scenarios leading to disproportionately high use of specialist 


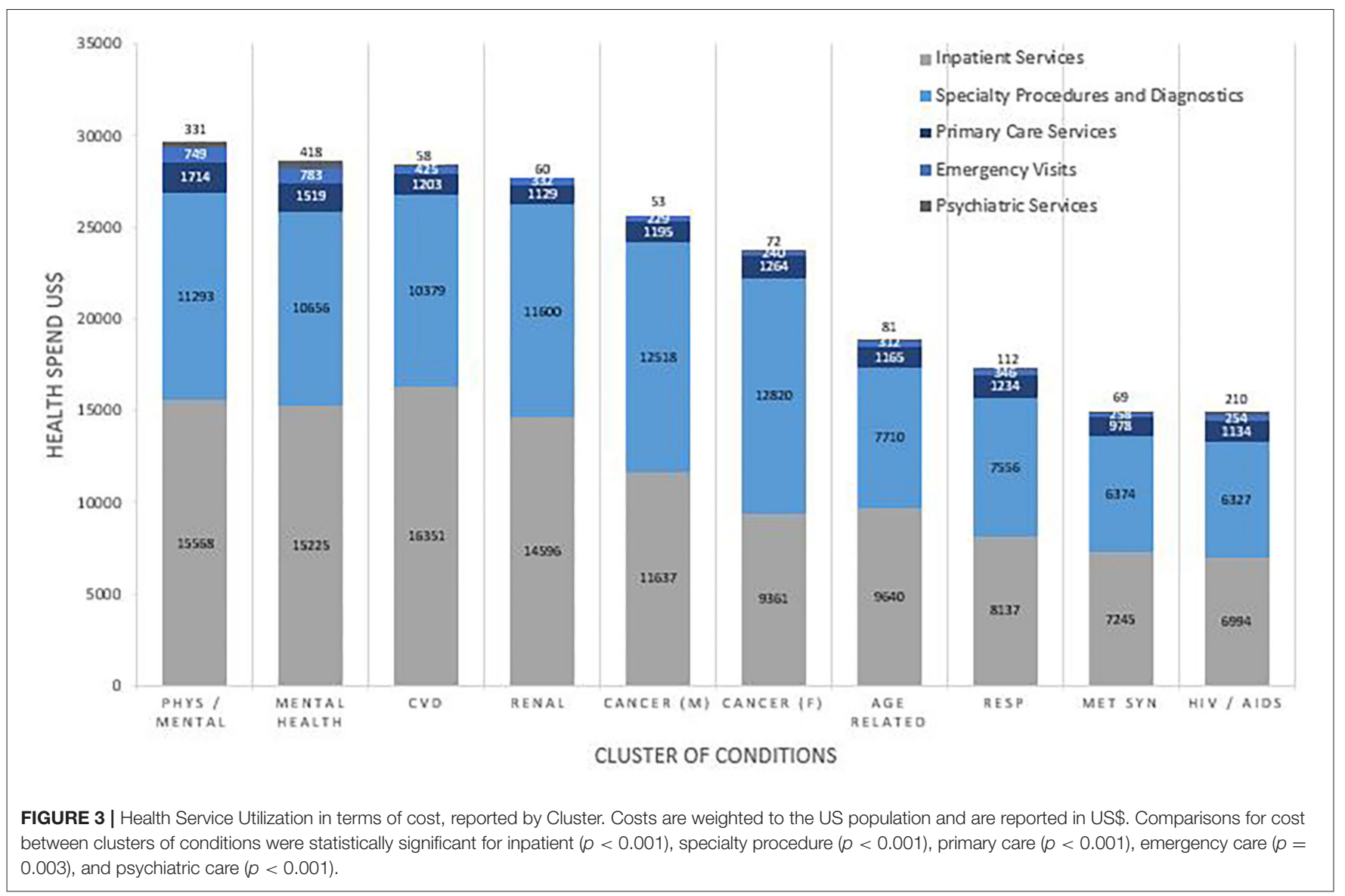

services, visits to a multitude of physicians and confronting physicians with more problems at each visit $(6,7)$. MCCs patients have been reported as having more prescription medications (polypharmacy) and higher prescription drug expenditures (8, 9). However, our findings suggest that, other than for certain clusters, high utilization of medical services is the principle factor in the elevated MCC cost burden.

Patient factors previously reported to determine cost and healthcare utilization have included age, living arrangements (e.g., living alone), being female and having supplementary insurance (24-27). Our study shows that they may also be influenced by the number and clustering of chronic conditions.

\section{Costs and Number of Conditions}

Our study shows a modest increase in healthcare spending, and that the relative increase tapers off, with each subsequent chronic condition. A few previous studies reported healthcare spending doubling with each additional chronic condition $(4,5)$ whilst others reported smaller increments (3). As our study is much larger and includes the full spectrum of chronic conditions, it is likely to be more representative of the overall status for chronic conditions.

\section{Clusters}

This is one of the most comprehensive studies to date that identifies and quantifies clustering between the full range of chronic conditions. Conditions may cluster together by virtue of independently high prevalence rates, shared risk factors, and disease pathways or due to the causation of one condition by another, and clusters may fall into more than one of these categories (10). The commonly occurring clusters identified here were a mixture of these types: shared high prevalence rates predominantly explaining the metabolic syndrome, CVD and age-related clusters; shared risk factors for cancers and renal failure; causation of subsequent conditions for clusters with mental health disorders, chronic pain, and HIV/AIDS. Further research is required to delineate the causal pathways and also to enable the prediction of subsequent chronic conditions. Regardless of the category of clustering, the high levels of association between chronic conditions should inform healthcare redesign with a cluster-based and multiple-condition approach.

The clusters identified may vary according to the method employed such as the strength of clustering and the frequency or size of the cluster. However, in our analysis there was a high level of concordance between the three methods employed. There is no fixed methodology for defining clusters and it is an area that requires further research, including the methodology of 
identifying clusters and of their categorization into concordant and discordant clusters.

\section{Healthcare Utilization}

Overall, inpatient services account for the highest increase in health spending with a 22 -fold increase between having 2 and 11 conditions whilst increments in other costs such as outpatient services and medications were much lower at between 4 - and 6- fold. This emphasizes the need for improved healthcare delivery to achieve greater chronic disease control and secondary prevention, as being key to cost containment in MCCs.

The value of healthcare spending per patient and patterns of utilization vary greatly by cluster regarding relative spending on medical vs. pharmaceutical costs, but less so between the medical services of primary, specialist, inpatient, psychiatric, and emergency care. The largest single category of healthcare spending was for branded drugs in patients with the HIV/AIDS cluster. Mental health clusters accounted for the second and third highest healthcare spending, higher than the CVD, cancer and renal failure clusters, and with the greatest spending, approximately half, on outpatient services.

The decrement of relative spending in primary care with each additional condition accrued suggests health system changes that enable MCC patients to be managed for longer in primary care could be hugely cost-saving. Spending on psychiatric services was low in all clusters, even in those clusters in which mental health disorders are present in over $95 \%$ of patients, suggesting underutilization of psychiatric specialist services in those who could benefit. The high overall health spending in mental health clusters may reflect poorer management of additional chronic conditions (10). Investment of resources to ensure that such patients have adequate access to healthcare for their mental health disorders is necessary to improve both the health and cost burden in such patients.

\section{Demographic Variation}

Age was not indicative of cost for all clusters; this finding for CVD and renal failure in particular are noteworthy and strengthen the case for primary prevention with a view to compression of morbidity to older ages.

Our study did not investigate variation by socio-economic status at individual level. Previous studies have shown in most countries a strong, negative relationship between SES and MCC among adults under 55 years but no consistently for adults older than 55 years (28). Inequalities in access to CVD medications have been shown both between countries and by income status within countries (29).

\section{Implications for Health Policy}

Clusters are highly amenable to large improvements in health and cost outcomes through relatively simple shifts in healthcare delivery such as the use of joint disease guidelines that tackle more than one common condition in a cluster, tailored screening and prevention. Healthcare payment mechanisms in developed countries often reward activity rather than desirable outcomes; shifting toward payment for quality or outcomes would facilitate better management of MCCs.
The variable clustering of certain chronic conditions more than others warrants urgent and careful consideration in light of the strength of such associations and the potential to have considerable impact through relatively small shifts in healthcare delivery. Our findings suggest mental health disorders may warrant particular attention through further recognition, prevention and screening practices, and disease management, due to the increased costs of clustering with mental health disorders. The relatively recent phenomenon of co-existence and clustering of chronic communicable conditions, such as HIV, with highly-prevalent NCDs, represents a serious threat for a failure of management of these conditions and increase in their prevalence, further complicated by poor healthcare access. Learnings from the successful delivery of HIV programs may be relevant to develop multiple disease frameworks, such as integrated care for NCDs and HIV in Kenya (30) and medication adherence clubs (31).

As many of the most frequent clusters identified in our study, such as metabolic syndrome, CVD, mental health issues and cancers, are highly amenable to modification, greater emphasis should be placed on the role of primary prevention and lifestyle behavior change to avoid the predicted rise in MCCs (32-34). A study in India reported MCC rates to be highest in adults with the risk factors of alcohol (12.3\%), overweight (14.1\%) and central obesity (17.1\%) (23).

Future work on healthcare delivery toward MCC should address its many challenges of disease burden, functional health, quality of life and healthcare costs, as well as issues related to polypharmacy.

\section{LIMITATIONS}

Although the data used in this study are US based, the findings are likely to be representative for developing countries which have similar disease burdens, namely death and disability combined due to IHD, drug use disorders, back pain and other musculoskeletal disorders, COPD, DM, depression, lung cancer, and stroke (35). The contributors to costs and relative costs between clusters would be similar in developing countries as these are largely determined by the disease burden. Other findings, such as absolute healthcare spending may be less generalizable to other health systems.

Certain chronic communicable conditions, such as TB, form important clusters in LMIC (36) but without sufficient prevalence in the US for TB, were not a focus of this study with the exception of HIV/AIDS. The findings of this study are not envisaged to represent healthcare costs in LMIC where communicable conditions are prevalent.

The costs reported in this study are of total healthcare spending as it would not be feasible to distinguish costs accrued specifically from episodes directly related to chronic conditions. In addition, only costs toward healthcare appearing in financial claims were included such that other costs were not reported e.g., out of pocket expenses that have been reported to also increase for MCC patients (37). 
There is no agreed taxonomy for MCCs leading to heterogeneity in the number of conditions included and whether those include symptoms and risk factors in addition to disease end-points (10-13). Furthermore, the interaction between clusters of conditions, for example concordant vs. discordant clustering, is also important to study for purposes of prediction and prevention of subsequent chronic conditions (10).

\section{CONCLUSION}

In one of the most comprehensive studies to investigate MCCs, we have reported that when applied to the US population, over half of the adult insured population have MCCs, identified the most important clusters and quantified the healthcare spending for MCCs and clusters, in a representative US patient sample. We identified that inpatient care accounts for the highest proportion of the increased spending overall but that utilization varies greatly by clusters, which is more predictive than other patient factors. Specific healthcare interventions for MCCs should take into account the local disease burden with regards to clusters. The findings emphasis the need in any long-term strategy to focus on primary prevention as the majority of the top clusters are amenable to prevention through lifestyle behavior change. In the short and medium term, health systems should focus on secondary prevention and disease control to reduce inpatient admissions. Greater reliance on specialist care may be necessary due to the greater complexity of care, however this is inefficient whilst delivered vertically for individual conditions when one in three adults have more than one chronic condition. The goal would be the delivery of care with a multi-disease framework rather than one condition at a time, in primary or secondary care. Examples of this are emerging in developing countries for HIV and $\operatorname{CVD}(30,31,38)$.

Interventions for MCCs with proven health and cost outcomes are lacking. Certain interventions have started to show early impact, including the use of fixed dose

\section{REFERENCES}

1. Violan C, Foguet-Boreu Q, Flores-Mateo G, Salisbury C, Blom J, Freitag $\mathrm{M}$, et al. Prevalence, determinants and patterns of multimorbidity in primary care: a systematic review of observational studies. PLoS ONE. (2014) 9:e102149. doi: 10.1371/journal.pone.0102149

2. Marengoni A, Angleman S, Melis R, Mangialasche F, Karp A, Garmen A, et al. Aging with multimorbidity: a systematic review of the literature. Ageing Res Rev. (2011) 10:430-9. doi: 10.1016/j.arr.2011.03.003

3. McPhail SM. Multimorbidity in chronic disease: impact on health care resources and costs. Risk Manage Healthc Policy. (2016) 9:143-56. doi: 10.2147/RMHP.S97248

4. Schneider KM. O'Donnell BE, Dean D. Prevalence of multiple chronic conditions in the United States' Medicare population. Health Qual Life Outcomes. (2009) 7:82. doi: 10.1186/1477-7525-7-82

5. Wolff JL, Starfield B, Anderson G. Prevalence, expenditures, and complications of multiple chronic conditions in the elderly. Arch Intern Med. (2002) 162:2269-76. doi: 10.1001/archinte.162.20.2269 combination pills to improve medication adherence and tackle undertreatment (39), cross-condition and symptombased management guidelines, and community models of healthcare delivery (40-42). Additional research is required to identify which interventions are impactful. Future chronic disease prevention and control approaches should be broad and patient-centric, taking into consideration healthcare payment mechanisms, the use of digital technology, tools to help with medication use and interventions to achieve positive lifestyle change, in order to avert the alarming projections of increases in MCCs rates.

\section{DATA AVAILABILITY STATEMENT}

Publicly available datasets were analyzed in this study. This data can be found at: Marketscan database, available to license through Truven Health Analytics.

\section{AUTHOR CONTRIBUTIONS}

$\mathrm{CH}$ designed the study, oversaw the data analysis, and wrote the manuscript. YS oversaw the data analysis, designed the study, and provided input to the manuscript. AA-W reviewed and provided input to the manuscript. All authors contributed to the article and approved the submitted version.

\section{ACKNOWLEDGMENTS}

The study used data from the Marketscan database, available to license through Truven Health Analytics (13). This manuscript has been released as a pre-print at Medxriv (43).

\section{SUPPLEMENTARY MATERIAL}

The Supplementary Material for this article can be found online at: https://www.frontiersin.org/articles/10.3389/fpubh. 2020.607528/full\#supplementary-material
6. Anderson, GF. Chronic Care: Making the Case for Ongoing Care. Robert Wood Johnson Foundation (2010). Available online at http://www.rwjf.org/ files/research/50968chronic.care.chartbook.pdf (accessed March 3, 2018).

7. Beasley JW, Hankey TH, Erickson R, Stange KC, Mundt M, Elliott M, et al. How many problems do family physicians manage at each encounter? A WReN study. Ann Fam Med. (2004) 2:405-10. doi: 10.1370/afm.94

8. Mueller C, Schur C, O'Connell J. Prescription drug spending: the impact of age and chronic disease status. Am J Public Health. (1997) 87:1626-9.

9. Sambamoorthi U, Shea D, Crystal S. Total and out-of-pocket expenditures for prescription drugs among older persons. Gerontologist. (2003) 43:345-59. doi: 10.1093 /geront/43.3.345

10. Hajat $\mathrm{C}$, Stein $\mathrm{E}$. The global burden of multiple chronic conditions: a narrative review. Prev Med Rep. (2018) 12:284-93. doi: 10.1016/j.pmedr.2018.10.008

11. Hajat C, Stein E, Yach D. Multiple Chronic Conditions: The Global State. (2017). Available online at: https://lnkd.in/etb9eAJ (accessed May 3, 2018).

12. Hajat C, Kishore SP. The case for a global focus on multiple chronic conditions. BMJ Glob Health. (2018) 3:e000874. doi: 10.1136/bmjgh-2018-000874 
13. Academy of Medical Science. Multimorbidity: A Priority for Global Health Research. (2018). Available online at: https://acmedsci.ac.uk/file-download/ 82222577 (accessed June 27, 2018).

14. Truven Health Marketscan database. Available online at: https://marketscan. truvenhealth.com/marketscanportal/ (accessed May 3, 2018).

15. Centers for Medicare and Medicaid Services. Available online at: https://www. cms.gov/ (accessed April 1, 2019).

16. International Classification of Disease. Available online at: https://www.who. int/classifications/icd/en/ (accessed April 1, 2019).

17. The Agency for Healthcare Research and Quality Chronic Conditions list. Available online at: https://www.hcup-us.ahrq.gov/toolssoftware/chronic/ chronic.jsp\#codes (accessed May 3, 2018).

18. MacQueen JB. Some methods for classification and analysis of multivariate observations. In: Proceedings of 5th Berkeley Symposium on Mathematical Statistics and Probability Vol 1. Al Ain: University of California Press (1967) p. 281-97.

19. Barnett JC, Vornovitsky MS. Health Insurance Coverage in the United States: 2015. (2016). Available online at: https://www.census.gov/library/ publications/2016/demo/p60-257.html (accessed February 1, 2018).

20. Ward BW, Schiller JS, Goodman RA. Multiple chronic conditions among US adults: a 2012 update. Prev Chronic Dis. (2014) 11:E62. doi: $10.5888 /$ pcd11.130389

21. Salisbury C, Johnson L, Purdy S, Valderas JM, Montgomery AA. Epidemiology and impact of multimorbidity in primary care: a retrospective cohort study. $\mathrm{Br}$ J Gen Pract. (2011) 61:e12-21. doi: 10.3399/bjgp11X548929

22. Garin N, Koyanagi A, Chatterji S, Tyrovolas S, Olaya B, Leonardi M, et al. Global multimorbidity patterns: a cross-sectional, population-based, multi-country study. J Gerontol A Biol Sci Med Sci. (2016) 71:205-14. doi: 10.1093/gerona/glv128

23. Singh K, Patel SA, Biswas S, Shivashankar R, Kondal D, Ajay VS, et al. Multimorbidity in South Asian adults: prevalence, risk factors and mortality. J Public Health. (2018) 41:80-9. doi: 10.1093/pubmed/fdy017

24. Rapoport J, Jacobs P, Bell NR, Klarenbach S. Refining the measurement of the economic burden of chronic diseases in Canada. Chronic Dis Can. (2004) 25:13-21.

25. Shelton P, Sager MA, Schraeder C. The community assessment risk screen (CARS): identifying elderly persons at risk for hospitalization or emergency department visit. Am J Manage Care. (2000) 6:925-33.

26. Landi F, Onder G, Cesari M, Barillaro C, Lattanzio F, Carbonin PU, et al. Comorbidity and social factors predicted hospitalization in frail elderly patients. J Clin Epidemiol. (2004) 57:832-6. doi: 10.1016/j.jclinepi.2004.01.013

27. Librero J, Peiró S, Ordiñana R. Chronic comorbidity and outcomes of hospital care: length of stay, mortality, and readmission at 30 and 365 days. J Clin Epidemiol. (1999) 52:171-9.

28. Afshar S, Roderick PJ, Kowal P, Dimitrov BD, Hill AG. Multimorbidity and the inequalities of global ageing: a cross-sectional study of 28 countries using the World Health Surveys. BMC Public Health. (2015) 15:776. doi: 10.1186/s12889-015-2008-7

29. Murphy A, Palafox B, O'Donnell O, Stuckler D, Perel P, AlHabib KF, et al. Inequalities in the use of secondary prevention of cardiovascular disease by socioeconomic status: evidence from the PURE observational study. Lancet Glob Health. (2018) 6:e292-301. doi: 10.1016/S2214-109X(18)30031-7

30. Mwangemi, F, Lamptey P. Integration of HIV and CVD services in Kenya. In: Oral presentation, HIV and Health Systems Pre-conference. Vienna (2010).

31. Green A. NIH project focuses on integration of HIV and NCD care. Lancet. (2016) 388:1869. doi: 10.1016/S0140-6736(16)31846-3

32. Islami F, Goding Sauer A, Miller KD, Siegel RL, Fedewa SA, Jacobs EJ, et al. Proportion and number of cancer cases and deaths attributable to potentially modifiable risk factors in the United States. CA Cancer J Clin. (2018) 68:31-54. doi: $10.3322 /$ caac. 21440

33. Schuh FB, Vancampfort D, Firth J, Rosenbaum S, Ward PB, Silva ES, et al. Physical activity and incident depression: a meta-analysis of prospective cohort studies. Am J Psychiatry. (2018) 175:631-48. doi: 10.1176/appi.ajp.2018.17111194

34. Hajat C, Selwyn A, Harris M, Yach D. Preventive interventions for the second half of life: a systematic review. Am J Health Promot. (2018) 32:1122-39. doi: 10.1177/0890117117712355

35. Global Burden of Disease data. Institute of Health Metrics and Evaluation. Available online at: http://www.healthdata.org/united-states (accessed November 12, 2020).

36. Jeon CY, Murray MB. Diabetes mellitus increases the risk of active tuberculosis: a systematic review of 13 observational studies. PLoS Med. (2008) 5:e152. doi: 10.1371/journal.pmed.0050152

37. Sum G, Hone T, Atun R, Millett C, Suhrcke M, Mahal A, et al. Multimorbidity and out-of-pocket expenditure on medicines: a systematic review. BMJ Glob Health. (2018) 3:e000505. doi: 10.1136/bmjgh-2017-000505

38. Uebel KE, Fairall LR, van Rensburg DH, Mollentze WF, Bachmann MO, Lewin $\mathrm{S}$, et al. Task shifting and integration of HIV care into primary care in South Africa: the development and content of the streamlining tasks and roles to expand treatment and care for HIV (STRETCH) intervention. Implement Sci. (2011) 6:86. doi: 10.1186/1748-5908-6-86

39. Rodgers A. A cure for cardiovascular disease? Combination treatment has enormous potential, especially in developing countries. BMJ. (2003) 326:1407-8. doi: 10.1136/bmj.326.7404.1407

40. Fairall LR, Zwarenstein M, Bateman ED, Bachmann M, Lombard C, Majara BP, et al. Effect of educational outreach to nurses on tuberculosis case detection and primary care of respiratory illness: pragmatic cluster randomised controlled trial. BMJ. (2005) 331750-4. doi: $10.1136 / \mathrm{bmj} .331 .7519 .750$

41. Fairall LR, Bachmann MO, Louwagie GM, van Vuuren C, Chikobvu P, Steyn D, et al. Effectiveness of antiretroviral treatment in a South African program: a cohort study. Arch Intern Med. (2008) 168:86-93. doi: 10.1001/archinternmed.2007.10

42. Fairall LR, Folb N, Timmerman V, Lombard C, Steyn K, Bachmann MO, et al. Educational outreach with an integrated clinical tool for nurse-led noncommunicable chronic disease management in primary care in South Africa: a pragmatic cluster randomised controlled trial. PLoS Med. (2016) 13:e1002178. doi: 10.1371/journal.pmed.1002178

43. Hajat C, Siegal Y, Adler-Waxman A. Clustering and healthcare costs with multiple chronic conditions in a US cross-sectional study. medRxiv [Preprint]. (2020) doi: 10.1101/2020.08.24.20179184

Conflict of Interest: $\mathrm{CH}$ and YS received funding from TEVA Pharmaceutical Industries Ltd for their time to conduct the study but did not receive funding to publish the study. AA-W is an employee of TEVA Pharmaceutical Industries Ltd. $\mathrm{CH}$ has received consulting fees from ECLAT, a spin-off of the University of Catania for tobacco harm reduction research, and was a paid member by Sustainability of the Advisory Panel for the Tobacco Transformation Index.

Copyright (c) 2021 Hajat, Siegal and Adler-Waxman. This is an open-access article distributed under the terms of the Creative Commons Attribution License (CC BY). The use, distribution or reproduction in other forums is permitted, provided the original author(s) and the copyright owner(s) are credited and that the original publication in this journal is cited, in accordance with accepted academic practice. No use, distribution or reproduction is permitted which does not comply with these terms. 